\title{
NETS FOR PEACH PROTECTED CULTIVATION
}

\author{
Evelia Schettini
}

\section{Introduction}

In agriculture plastic nets are mounted on screenhouse structures or above greenhouse covering materials in order to protect plants from adverse weather conditions, such as wind, hail and frost, and also from birds and aphids. The use of plastic nets is expanding in Southern European countries in order to reduce the entering of solar radiation and consequently the air temperature inside the protected volume during the warmest periods, so that nets mitigate the microclimate inside the screen-house or greenhouse [Briassoulis 2007a].

Nets are characterised by a mesh density ranging from 10 to 200 mesh $\mathrm{cm}^{-2}$ in relation to their use as anti-hail, windbreak, anti-insect or shading net [Briassoulis 2007b; Castellano 2008]. Nets, available in different shading factors, are generally made with polypropylene (PP) or high density polyethylene (HDPE). The shading factor, varying from $10 \%$ to 90 $\%$, represents the capacity of the net to reduce the incoming solar radiation and it is usually measured by means of luxmeters, thus it can be related to the solar radiation wavelength band which extends from 380 to $760 \mathrm{~nm}$, including the photosynthetically active radiation (PAR) range from 400 to $700 \mathrm{~nm}$. The shading factor is related to the average value of the transmissivity of the net in the solar range, but it does not give information about the spectral distribution of the radiation in such an interval. Information about the spectral distribution of the radiation passing through the net can be obtained measuring the spectral transmissivity $\tau(\lambda)$, which is the fraction of the incident energy radiant flux that is transmitted at a specific wavelength $\lambda$.

Nets are extensively used in fruit-tree farming [Briassoulis 2007b]. One of the principal problems with

Paper received 15.06.2011; accepted 10.10.2011

Ing. Evelia SCHETtini: Department of Agricultural and Environmental Science, University of Bari, via Amendola 165/A 70126 Bari (Italy); (evelia.schettini@agr.uniba.it). Tel. 0039.0805443060, fax 0039.0805442977 protected tree cultivation is the control of plant height, which can be achieved with the use of growth regulators [Wilson 2001] but is preferably accomplished with agronomic techniques including dwarfing rootstocks, a regulated irrigation deficit, and a modified radiation environment [Clifford 2004; Dichio 2004; Rajapakse 1999; Shahak 2004]. Alterations of spectral wavelength distribution and the quantity of solar radiation influence plant growth, development, and productivity, so that a modified radiation environment can be used for the vegetative control for trees cultivated inside a protected volume instead of the use of growth regulators [Rajapakse 1994]. Changes in red radiation ( $R$, 600$700 \mathrm{~nm}$ ), in far-red radiation (FR, 720-740 nm), or in blue radiation (B, $400-500 \mathrm{~nm}$ ) in the growing environment affect plant photomorphogenesis, involving the activation of photoreceptors, such as the phytochrome and the cryptochrome. It has become common practice to characterize the phytochrome response in terms of the bichromatic $\mathrm{R} / \mathrm{FR}$ ratio of the photon fluence rate in the red to that in the far-red [Baraldi 1994; Kittas 1998; Kittas 1999; Murakami 1996; Oren-Shamir 2001; Smith 1982; Takaichi 2000; Wilson 2001]. Few studies investigated the effects of the blue radiation on the morphogenetic responses of plants [Kittas 1999; Moe 2002; Schettini 2011a] by means of the ratio of $\mathrm{B} / \mathrm{FR}$ radiation, a cryptochrome-related parameter.

The aim of this paper is to investigate the influence of the radiometric properties of coloured nets on peach tree morphogenesis, by studying the modification of the spectral distribution of the transmitted radiation and thus the effects on the peach tree vegetative cycle and on fruit quality parameters. A field cultivation test using coloured nets for the protection of peach trees was carried out. The effects of the nets on the trees growth were correlated with the radiometric properties of the nets, which were evaluated by means of laboratory tests.

\section{Materials and methods}

Plastic coloured nets were tested as covering materials for horticultural greenhouses at the experimental 


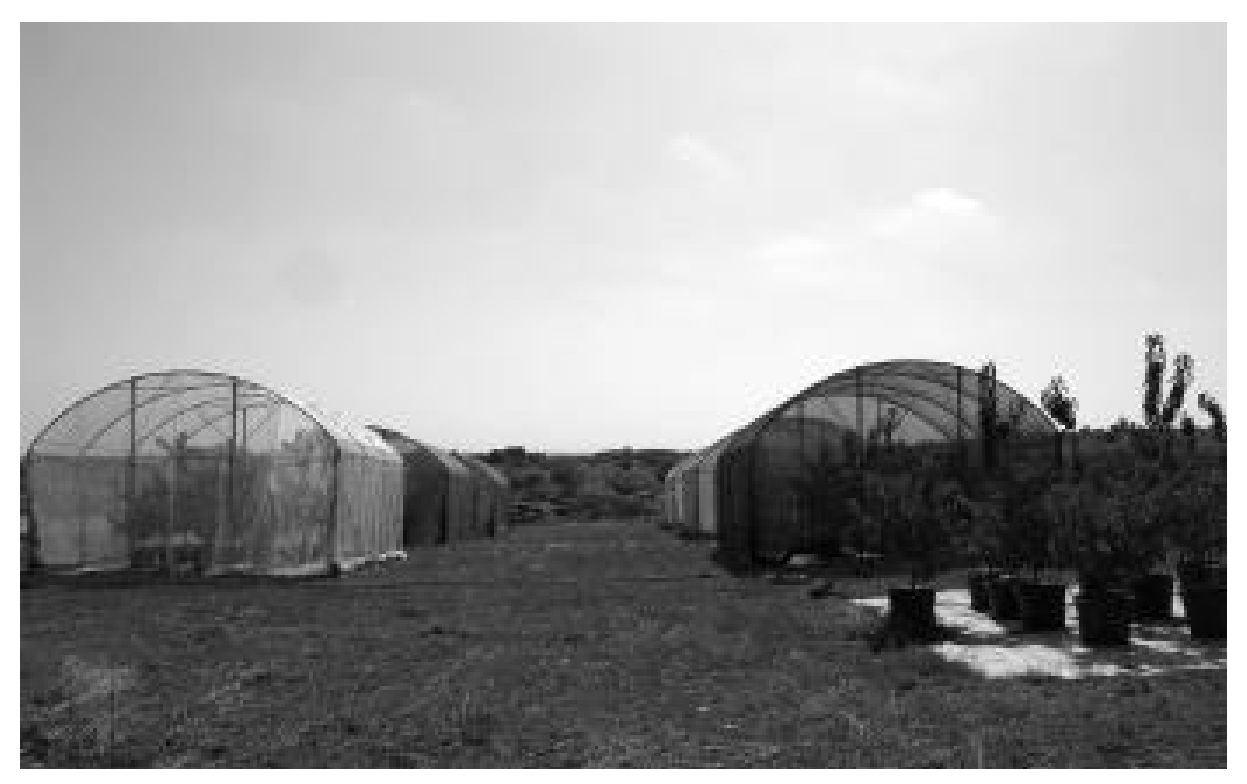

Fig. 1 - The greenhouses covered with the nets at the experimental field of the University of Bari (Italy).

farm of the University of Bari in Valenzano (Bari, Italy; $41^{\circ} 05^{\prime} \mathrm{N}, 16^{\circ} 53^{\prime} \mathrm{E}, 85 \mathrm{~m}$ asl) from 2008 to 2010. Five coloured nets, a BLUE, a RED, a PEARL, a GREY and a YELLOW net, with a nominal shading factor of $40 \%$, and a NEUTRAL net, with a nominal $12 \%$ shading factor, were used for peach protected cultivation (Fig. 1). The coloured nets, with the trademark ChromatiNet (Polysack Plastic Industries Ltd., Israel), and the neutral one, with the trademark Monotex 30 (Polysack Plastic Industries Ltd., Israel) were provided by the AGRITENAX Company (Eboli, Salerno, Italy). Each net was installed on an EastWest oriented steel arched roof greenhouse $(6.0 \mathrm{~m} \mathrm{x}$ $6.0 \mathrm{~m}$, ridge height of $3.8 \mathrm{~m}$, gutter height of $2.4 \mathrm{~m}$ ). One year old bare root peach trees ('Messapia') on Missour rootstock, grown in plastic pots $\left(35 \mathrm{dm}^{3}\right)$ containing a $2: 1(\mathrm{v} / \mathrm{v})$ mixture of soil and peat, were placed inside the greenhouses and in open field. Peach trees in open field conditions were used as the control. The experiment was carried out using 6 trees for each treatment; each single tree was considered to be an experimental unit, in agreement with Pearce [1983]. All the trees were uniformly irrigated and fertilized by an automated drip irrigation system.

All the trees reached a significative volume of the canopy in 2010, thus vegetative and cropping data were measured. To evaluate the vegetative activity of the trees, in each treatment the length of twigs grown during 2010 ( 5 for each tree) was randomly measured at the end of the season; these measurements were used to calculate the average seasonal twig growth and the internode length. At harvest, total yield, average fruit weight and flesh firmness were measured to evaluate peach fruit quality. Flesh firmness was evaluated on 30 fruits per treatment by means of a penetrometer. Firmness measurements were based on the pressure required to push a plunger of specified dimensions into the pulp of the fruit up to a specific depth in order to determine the stage of ripeness of the fruits.

Radiometric tests on the nets were carried out at the "Laboratory for the Measurement of the Radiometric Properties of Materials" at the University of Bari by means of spectrophotometers in order to evaluate the spectral transmissivity $\tau(\lambda)$ of the nets. Spectral direct transmissivity of the nets in the solar range was measured by a double beam UV-VIS-NIR spectrophotometer (Lambda 950, Perkin Elmer Instruments, Norwalk, CT, USA); measurements were carried out in the wavelength band from 200 to $2500 \mathrm{~nm}$ in steps of $10 \mathrm{~nm}$ using radiation with a direct perpendicular incidence. Spectral total transmissivity was measured by means of an integrating sphere (diameter $60 \mathrm{~mm}$ ) used as the receiver of the Lambda $950 \mathrm{spec}-$ trophotometer, with a double beam comparative method [Wendlandt 1966]. Spectral diffuse transmissivity was calculated by subtracting the direct transmissivity from the total transmissivity. Radiometric properties of the covering materials were defined by means of the transmissivity coefficients calculated as average values of the spectral transmissivity over different wavelength bands: the solar wavelength range $(300-2500 \mathrm{~nm})$, the PAR range $(400-700 \mathrm{~nm})$ and the long wave infrared radiation (LWIR) range $(>3000$ $\mathrm{nm})$. The transmissivity coefficients in the solar range were calculated as the weighted average value of the spectral transmissivity over the wavelength intervals using the spectral distribution of the terrestrial solar radiation at the ground level as weighting function [Duffie 1991; Papadakis 2000; Vox 2007].

Spectral transmissivity in the LWIR range, between $2500 \mathrm{~nm}$ and $25000 \mathrm{~nm}$, was measured by a FT-IR spectrophotometer (1760 X, Perkin Elmer Instruments, Norwalk, CT, USA), in steps of $4 \mathrm{~cm}^{-1}$, using radiation with a direct perpendicular incidence. The LWIR transmissivity coefficient was calculated 
as the average value over the wavelength interval $7500 \mathrm{~nm}-12500 \mathrm{~nm}$, at which bodies at ambient temperature have the maximum energy emission as expressed by the Planck's spectral distribution of emissive power [Papadakis 2000; Siegel 1972, Vox 2007].

The ratio of the photon fluence rate in the red $(\mathrm{R}$, $650-670 \mathrm{~nm}$ ) to that in the far-red (FR, 720-740 nm), $\mathrm{R} / \mathrm{FR}$, and the ratio of the photon fluence rate in the blue (B, 400-500 $\mathrm{nm}$ ) to that in the far-red (FR, 720$740 \mathrm{~nm}), \mathrm{B} / \mathrm{FR}$, inside the greenhouses were calculated by means of:

$$
\begin{aligned}
& \frac{R}{F R}=\left(\frac{R}{F R}\right)_{n} \frac{\tau_{R}}{\tau_{F R}} \\
& \frac{B}{F R}=\left(\frac{B}{F R}\right)_{n} \frac{\tau_{z}}{\tau_{F R}}
\end{aligned}
$$

where the subscript $n$ refers to the value of R/FR and $\mathrm{B} / \mathrm{FR}$ ratios for the natural radiation, which were assumed to be 1.14 for R/FR and 3.75 for B/FR [Schettini 2011b]; $\tau_{R}, \tau_{F R}$ and $\tau_{B}$ are the transmissivity of the net in the R, FR and $B$ wavelength range, respectively.

\section{Results and discussion}

Figure 2 shows the spectral total transmissivity of the nets measured in the solar wavelength range, between 200 and $2500 \mathrm{~nm}$. The NEUTRAL net showed the highest spectral distribution of the transmissivity, with an increasing trend in the UV region and with a rather uniform trend in the PAR and in the solar infrared region. The RED, BLUE, YELLOW and PEARL nets were characterised by a non uniform transmissivity distribution in the PAR range; these nets increased their transmissivity at wavelengths higher than $800 \mathrm{~nm}$, in the solar infrared region, where solar radiation does not have direct influence on plant growth but contributes to increase the thermal level of the protected area. The GREY net was characterised by the lowest uniform transmissivity distribution in the PAR and in the solar infrared region.

The RED net had high values of transmissivity at wavelengths higher than $600 \mathrm{~nm}$, including the wavelength band which can be associated with the red colour, from $600 \mathrm{~nm}$ to $700 \mathrm{~nm}$. The BLUE net had a significant peak of transmissivity in the blue wavelength range, from 400 to $500 \mathrm{~nm}$, where the RED net showed lower values of transmissivity. The YELLOW net showed an increase of the transmissivity from the wavelengths higher than $500 \mathrm{~nm}$, including the wavelength band that can be associated with the yellow colour, from 570 to $600 \mathrm{~nm}$. The PEARL net increased its low transmissivity from the PAR region.

The spectral transmissivity of the nets measured in the LWIR wavelength range, between 2500 and $25000 \mathrm{~nm}$, is shown in Figure 3. The NEUTRAL net showed the highest rather uniform spectral distribution of the transmissivity in the LWIR region. All the coloured nets showed lower spectral distribution of the transmissivity in the LWIR region and the GREY net was characterised by the lowest uniform transmissivity.

The radiometric parameters of the nets, i.e. their transmissivity coefficients calculated in the solar, in the PAR, in the UV and in the LWIR wavelength range, are shown in Table 1. Among all the nets tested, the GREY net showed the lowest capacity to transmit solar radiation in the solar range, with the solar total transmissivity coefficient equal to $46.6 \%$, while the NEUTRAL net was characterised by the highest solar total transmissivity coefficient (89.7\%).

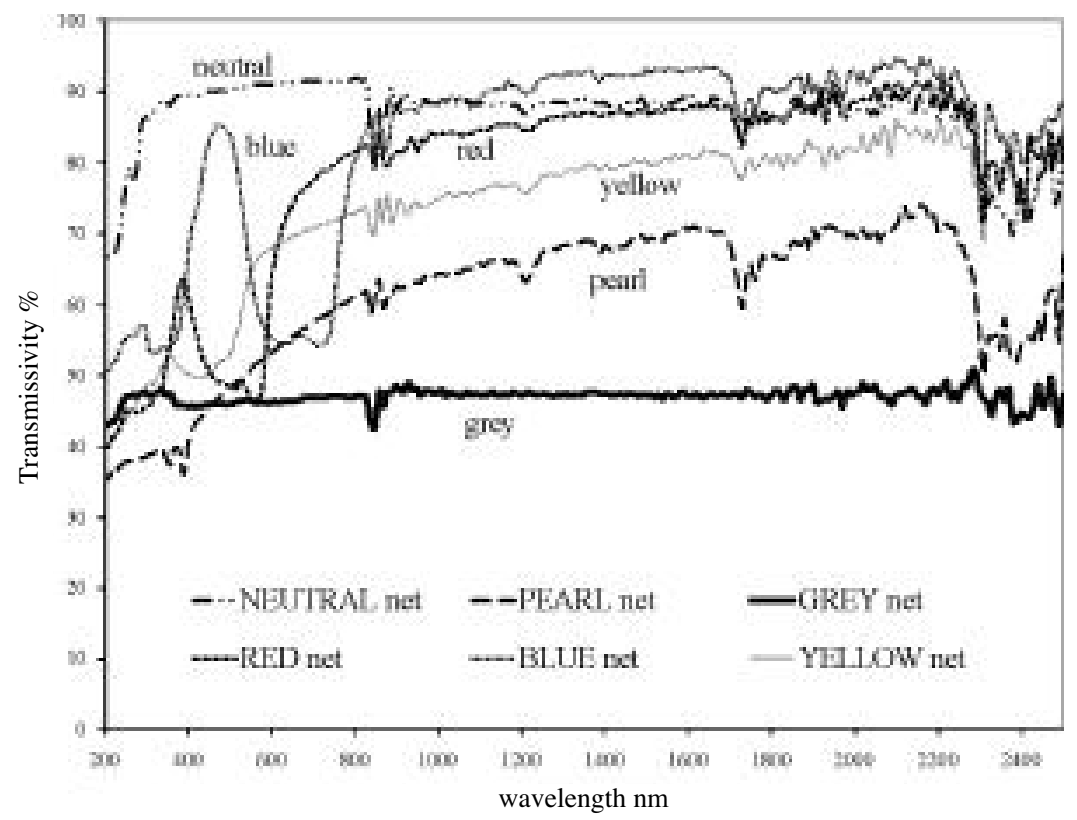

Fig. 2 - Total spectral transmissivity of the nets in the wavelength range $200-2500 \mathrm{~nm}$. 


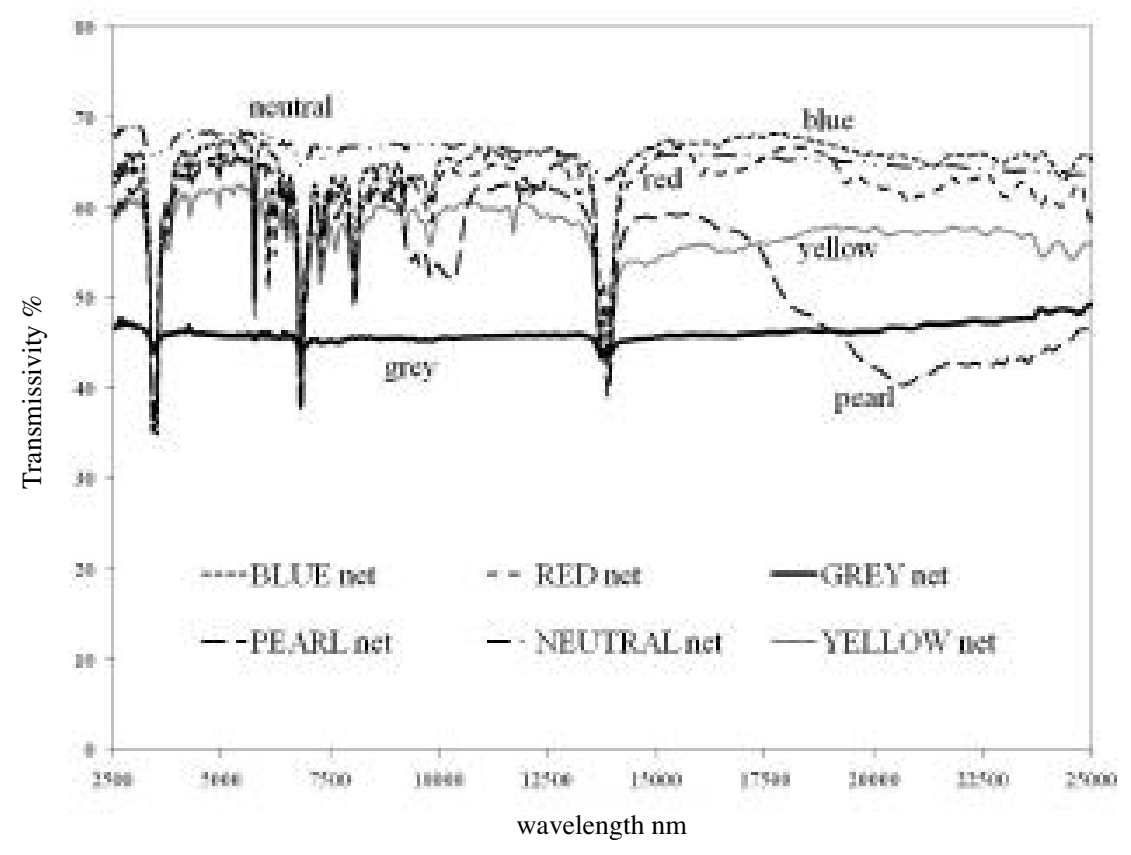

Fig. 3 - Long wave infrared (LWIR) spectral transmissivity of the nets in the wavelength range $2500-25000 \mathrm{~nm}$.

The solar total transmissivity coefficient of the RED net and the BLUE net was equal to $71.2 \%$ and $75.0 \%$, respectively; the PEARL and the YELLOW nets were less transparent to the solar radiation due to the solar total transmissivity coefficient equal to $57.1 \%$ and $68.2 \%$, respectively.

The RED, YELLOW and BLUE nets were characterised by the PAR total transmissivity equal to $58.2 \%$, $61.3 \%$ and $66.7 \%$, respectively, while the NEUTRAL net had the coefficient equal to $90.6 \%$. The PEARL and the GREY nets were less transparent to the PAR radiation.

The YELLOW net showed the highest capacity to diffuse solar radiation in the PAR range, with the PAR diffuse transmissivity coefficient equal to $27.5 \%$, while the GREY net showed the lowest PAR diffuse transmissivity coefficient $(5.4 \%)$.

The UV total transmissivity coefficient of the coloured nets was lower than the value evaluated for the NEUTRAL net $(88.6 \%)$, ranging from $39.0 \%$ (PEARL net) to $55.3 \%$ (RED net).

There were slight differences in the LWIR transmissivity between the RED, BLUE, PEARL and YELLOW nets and the NEUTRAL net: the LWIR transmissivity coefficient ranged from $58.9 \%$, for the PEARL and YELLOW nets, to $64.2 \%$, for the BLUE net, while the NEUTRAL net had the highest LWIR transmissivity coefficient, that is equal to $66.7 \%$. The GREY net showed the lowest LWIR transmissivity coefficient $(45.6 \%)$.

The transmissivity ratios, i.e. $\tau_{\mathrm{R}} / \tau_{\mathrm{FR}}$ and $\tau_{\mathrm{B}} / \tau_{\mathrm{FR}}$, and the photon fluence rate ratios in the red, far red and blue radiation range, i.e. the $\mathrm{R} / \mathrm{FR}$ ratio and the $\mathrm{B} / \mathrm{FR}$ ratio, evaluated in open field and inside the greenhouses covered with the nets are shown in Table 2. Compared to the R/FR ratio in open-field (equal to 1.14), the BLUE, GREY, YELLOW and NEUTRAL nets recorded a $\mathrm{R} / \mathrm{FR}$ ratio ranging from 1.11 (YELLOW net) to 1.15 (BLUE net). The R/FR radiation ratio was slightly modified by the RED and the PEARL net; these two nets were characterised by the R/FR ratio equal to 1.08 and 1.09, respectively. The GREY net and the NEUTRAL net were characterised by a B/FR ratio equal to 3.68 and 3.69 , respectively, similar to the value recorded in open-field (equal to 3.75). The RED and the BLUE nets showed the lowest and the highest ratio respectively: the RED net decreased the B/FR ratio of the natural radiation by $34 \%$, while the BLUE net increased it by $45 \%$.

The influence of the different coloured nets on the vegetative activity of the peach trees and on fruit quality at harvest was evaluated in 2010 .

As shown in Figure 4, the differences in one year old twig length were not statistically significative for the trees grown in OPEN FIELD, and inside the greenhouses covered with the NEUTRAL and the BLUE net; higher differences were recorded in comparison to open field for the trees grown under the RED (+43.0\%), PEARL (+50.8\%), YELLOW net $(+58.0 \%)$. The GREY net enhanced significantly the growth of seasonal twig length $(+67.9 \%)$ in comparison to the trees cultivated under the other nets and in OPEN FIELD.

The RED and PEARL nets, characterized by the $\mathrm{R} / \mathrm{FR}$ and $\mathrm{B} / \mathrm{FR}$ radiation ratios lower than the outdoor natural radiation parameters (Tab. 2), stimulated the vegetative activity by means of a direct influence on photomorphogenetic receptors [Young 1994]. The YELLOW and GREY nets induced the highest growth of the twigs: this can be related to their low solar radiation transmissivity coefficients (Tab. 1), that reduced physiological stress. 


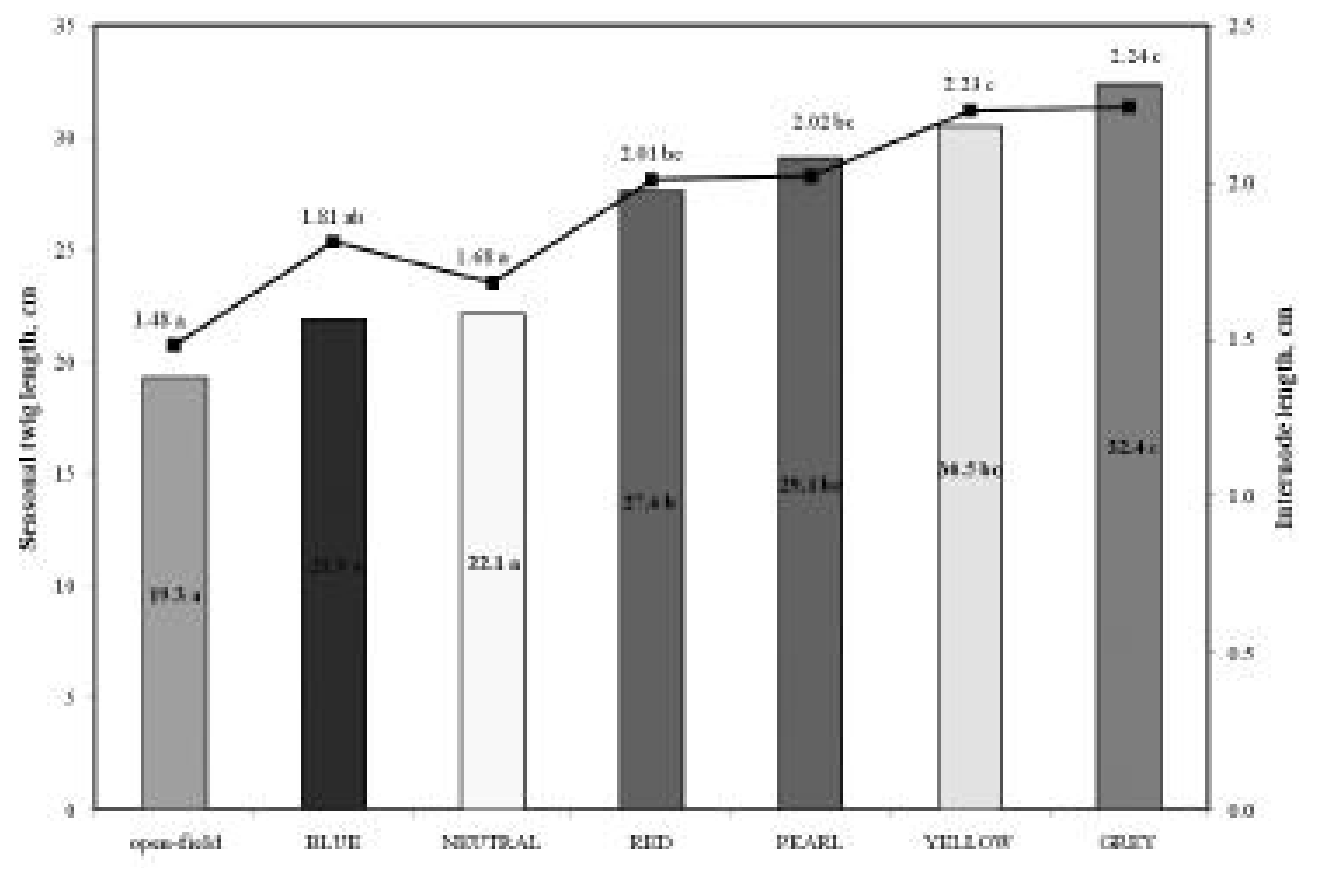

Fig. 4 - Seasonal twig length (histogram) and internode length (line) of the nets evaluated during 2010; the values followed by a different letter are statistically different at $\mathrm{P}=0.05$.

As shown in Table 3, the nets increased significantly the yield respect to OPEN FIELD without significative differences among the different nets tested. Significative differences were induced on ripening time and fruit quality parameters for the trees cultivated under the different nets. Mean fruit weight resulted, compared to OPEN FIELD, significantly reduced under the BLUE and GREY nets, similar under the RED and YELLOW nets while increased under the PEARL net.

Flesh firmness, decreasing during the maturation and ripening, can be used to determine how late fruits can be harvested and still ensure good quality after transport, shipping and marketing. At harvest, fruits

\begin{tabular}{|l|c|c|c|c|c|}
\hline & Solar total (\%) & PAR total (\%) & PAR diffuse (\%) & UV total (\%) & LWIR (\%) \\
\hline RED & 71.2 & 58.2 & 14.3 & 55.3 & 62.3 \\
\hline BLUE & 75.0 & 66.7 & 18.7 & 54.6 & 64.2 \\
\hline GREY & 46.6 & 46.1 & 5.4 & 46.6 & 45.6 \\
\hline PEARL & 57.1 & 50.8 & 15.9 & 39.0 & 58.9 \\
\hline YELLOW & 68.2 & 61.3 & 27.5 & 51.3 & 58.9 \\
\hline NEUTRAL & 89.7 & 90.6 & 23.6 & 88.6 & 66.7 \\
\hline
\end{tabular}

TABLE 1 - Transmissivity coefficients of the nets; PAR, photosynthetically active radiation; UV, ultra violet radiation; LWIR, long wave infrared radiation.

\begin{tabular}{|c|c|c|c|c|}
\hline & $\tau_{\mathrm{R}} / \tau_{\mathrm{FR}}$ & $\tau_{\mathrm{B}} / \tau_{\mathrm{FR}}$ & $\mathrm{R} / \mathrm{FR}$ & $\mathrm{B} / \mathrm{FR}$ \\
\hline RED & 0.95 & 0.66 & 1.08 & 2.49 \\
\hline BLUE & 1.01 & 1.45 & 1.15 & 5.42 \\
\hline GREY & 0.99 & 0.98 & 1.13 & 3.68 \\
\hline PEARL & 0.95 & 0.77 & 1.09 & 2.88 \\
\hline YELLOW & 0.98 & 0.71 & 1.11 & 2.67 \\
\hline NEUTRAL & 1.00 & 0.98 & 1.14 & 3.69 \\
\hline OPEN FIELD & -- & -- & 1.14 & 3.75 \\
\hline
\end{tabular}

TABLE 2 - Transmissivity ratios of the nets and photon fluence rate ratios outside (open field) and inside the greenhouses covered with the different nets; $\mathrm{R}$, red radiation range (650$670 \mathrm{~nm})$; FR, far-red radiation range $(720-740 \mathrm{~nm})$; B, blue radiation range $(400-500 \mathrm{~nm})$. 


\begin{tabular}{|c|c|c|c|c|}
\hline & $\begin{array}{c}\text { Yield per tree } \\
(\mathrm{kg})\end{array}$ & $\begin{array}{c}\text { Fruit weight } \\
(\mathrm{kg})\end{array}$ & $\begin{array}{c}\text { Flesh firmness } \\
\left(\mathrm{kg} / \mathrm{cm}^{2}\right)\end{array}$ & $\begin{array}{c}\text { Harvest delay or anticipation } \\
\text { (days) }\end{array}$ \\
\hline OPEN FIELD & $4.1 \mathrm{a}$ & $0.207 \mathrm{~b}$ & $3.20 \mathrm{a}$ & 0 \\
\hline NEUTRAL & $6.5 \mathrm{~b}$ & $0.259 \mathrm{~d}$ & $3.95 \mathrm{a}$ & +1.4 \\
\hline BLUE & $5.8 \mathrm{~b}$ & $0.183 \mathrm{a}$ & $4.81 \mathrm{~b}$ & +2.0 \\
\hline RED & $6.3 \mathrm{~b}$ & $0.210 \mathrm{~b}$ & $4.56 \mathrm{~b}$ & +2.5 \\
\hline YELLOW & $5.9 \mathrm{~b}$ & $0.199 \mathrm{~b}$ & $4.55 \mathrm{~b}$ & +2.7 \\
\hline PEARL & $5.3 \mathrm{~b}$ & $0.239 \mathrm{c}$ & $3.37 \mathrm{a}$ & -2.0 \\
\hline GREY & $5.4 \mathrm{~b}$ & $0.176 \mathrm{a}$ & $5.52 \mathrm{c}$ & +3.8 \\
\hline
\end{tabular}

In each column, values followed by different letter are statistically different at $\mathrm{P}=0.05$

TABLE $\quad 3$ - Yield and fruit quality parameters evaluated during 2010.

from OPEN FIELD and from the greenhouses covered with the PEARL net and with the NEUTRAL net were significantly softer (lower flesh firmness) than those of the other nets.

Among the nets and the OPEN FIELD, the PEARL net anticipated the harvest; the NEUTRAL, BLUE, RED and YELLOW nets delayed peach maturity in comparison with OPEN FIELD, with a maximum delay for the GREY net.

\section{Conclusions}

The experimental field test showed that it is possible to alter the quality of the solar radiation under covering plastic nets, thus influencing the growth, the vegetative activity and the fruit maturity time of the peach trees grown under the nets in comparison to open field.

The RED net and the PEARL net influenced the vegetative growth probably due to the reduction of their R/FR ratios in comparison to the outdoor natural radiation ratio, so that affected plant photomorphogenesis and phytochrome. For the YELLOW net and the GREY net the vegetative growth was mainly connected to their radiometric characteristics, thus reducing summer stress conditions. The vegetative growth was less manifest inside the greenhouses covered with the NEUTRAL net and the BLUE net; this was probably due both to their B/FR ratios, similar (3.69 for the NEUTRAL net) or higher (5.42 for the BLUE net) than the outdoor ratio (3.75), and to the presence of blue radiation $(\mathrm{B}, 400-500 \mathrm{~nm})$ in the growing environment, which has a depressive effect on tree growth [Cosgrove 1981]. Concerning the qualitative characteristics of the fruits, the PEARL net and the NEUTRAL net, as shown also in Shahak [2004], influenced positively the weight of the fruits.

It is necessary to continue research on photomorphogenesis both to elucidate the physiological mechanisms through which the plant controls its growth and to design new nets with specific radiometric properties that can meet the diverse needs of various sectors involved in tree protected cultivation. Such nets can be used in place of chemical growth regulators, thereby increasing the sustainability of the agricultural production.

\section{Acknowledgements}

The present work has been carried out under the Project "Research for the improvements of the fruit tree protected cultivation in Southern Italy FRU.MED.; subproject DAFME", funded by the Italian Ministry of Agriculture and Forestry Policy; publication $\mathrm{n}^{\circ} 91$.

The author thanks geom. M. Cosmo of the University of Bari for the spectrophotometric measurements, and Dr. C. Anifantis and Mr. F. Ferrulli of the University of Bari for their cooperation in the field tests.

\section{References}

Baraldi R., Rossi F., Facini O., Fasolo F., Rotondi A., Magli M., Nerozzi F., Light environment, growth and morphogenesis in a peach tree canopy. Physiologia Plantarum, 1994, 91, 339-345.

Briassoulis D., Mistriotis A., Eleftherakis D., Mechanical behaviour and properties of agricultural nets. Part I: Testing methods for agricultural nets. Polymer Testing, 2007a, 26, 882-832.

Briassoulis D., Mistriotis A., Eleftherakis D., Mechanical behaviour and properties of agricultural nets. Part II: Analysis of the performance of the main categories of agricultural nets. Polymer Testing, 2007b, 26, 970-984.

Castellano S., Scarascia Mugnozza G., Russo G., Briassoulis D., Mistriotis A., Hemming S., Waaijenberg D., Plastic Nets in Agriculture: a General Review of Types and Applications. Applied Engineering in Agriculture, 2008, 24 (6), 799-808.

Clifford S.C., Runkle E.S., Langton F.A., Mead A., Foster S.A., Pearson S., Heins R.D., Height control of poinsettia using photoselective filters. HortScience, 2004, 39 (2), 383-387.

Cosgrove D.J., Green P.B., Rapid suppression of growth by blue light. Plant Physiology, 1981, 68, 1447-1453.

Dichio B., Xiloyannis C., Nuzzo V., Montanaro G., Palese A.M., Posharvest regulated deficit irrigation of peach tree in a mediterranean enviroment: effects on vegetative growth and yield. Acta Horticulture, 2004, 664, 169174.

Duffie J.A., Beckman W.A., Solar engineering of thermal processes. John Wiley \& Sons, 1991, New York.

Kittas C., Baille A., Determination of the spectral properties of several greenhouse cover materials and evaluation of specific parameters related to plant response. Journal of 
Agricultural Engineering Research, 1998, 71, 193-202.

Kittas C., Baille A., Giaglaras P., Influence of covering material and shading on the spectral distribution of light in greenhouses. Journal of Agricultural Engineering Research, 1999, 73, 341-351.

Moe R., Morgan L., Grindal G., Growth and plant morphology of cucumis savitus and Fuchsia x hybrid are influenced by light quality during the photoperiod and by diurnal temperature alternations. Acta Horticulturae, 2002, 580, 229-234.

Murakami K., Cui H., Kiyota M., Takemura Y., Oi R., Aiga, I., Covering materials to control plant growth by modifying the spectral balance of daylight. Plasticulture, 1996, 110 (2), 2-14.

Oren-Shamir M., Gussakovsky E.E., Shpiegel E., NissimLevi A., Ratner K., Ovadia R., Giller Y.E., Shahak Y., Coloured shade nets can improve the yield and quality of green decorative branches of Pittosporum variegatum. Journal of Horticultural Science \& Biotechnology, 2001 76 (3), 353-361.

Papadakis G., Briassoulis D., Scarascia Mugnozza G., Vox G., Feuilloley P., Stoffers J.A., Radiometric and Thermal Properties of, and Testing Methods for, Greenhouse Covering Materials. Journal of Agricultural Engineering Research, 2000, 77 (1), 7-38.

Pearce S.C., The agricultural field experiment: a statistical examination of theory and practice. John Wiley \& Sons, 1983, New York, USA. 335 pp.

Rajapakse N. C., Kelly J. W., Influence of spectral filters on growth and postharvest quality of potted miniature roses. Scientia Horticulturae, 1994, 56, 245-255.

Rajapakse N. C., Young R. E., McMahon M. J., Oi R., Plant height control by photoselective filters: current status and future prospects. HortTechnology, 1999, 9 (4), 618624.

Schettini E., De Salvador F.R., Scarascia Mugnozza G., Vox G., Radiometric properties of photoselective and photoluminescent green house plastic films and their effects on peach and cherry tree growth. Journal of Horticultural Science \& Biotechnology, 2011a, 86 (1), 79-83.

Schettini E., De Salvador F.R., Scarascia Mugnozza G., Vox G., Evaluation of coloured nets in peach protected cultivation. Acta Horticulturae, 2011b, 893 (1), 235-242.

Shahak Y., Gussakovsky E.E., Cohen Y., Lurie S., Stern R., Kfir S., Naor A., Atzmon I., Doron I., Greenblat-Avron Y., ColorNets: a new approach for light manipulation in fruit trees. Acta Horticulturae, 2004, 636, 609-616.

Siegel R., Howell J.R., Thermal Radiation Heat Transfer. McGraw-Hill, 1972, New York

Smith, H., Light quality, photoperception, and plant strate- gy. Ann. Reviews of Plant Physiology, 1982, 33, 481518.

Takaichi M., Shimaji H., Higashide T., Effect of red/far-red photon flux ratio of solar radiation on growth of fruit vegetable seedlings. Acta Horticulturae, 2000, 514, 147156.

Vox G., Schettini E., Evaluation of the radiometric properties of starch-based biodegradable films for crop protection. Polymer Testing, 2007, 26 (5), 639-651.

Wendlandt W.W., Hecht H.G., Reflectance spectroscopy, John Wiley and Sons, New York, 1966, 253-274.

Wilson S. B., Rajapakse N.C., Use of photoselective plastic films to control growth of three perennial salvias. Journal of Applied Horticulture, 2001, 3 (2), 71-74.

Young R.E., McMahon M.J., Rajapakse N.C., Decoteau D.R., Spectral filtering for plant production. International Lighting in Controlled Environments Workshop. Tibbitts T.W Ed., 1994, NASA- CP- 95- 3309.

\section{SUMMARY}

The aim of this paper was to investigate the radiometric properties of coloured nets used to protect a peach cultivation. The modifications of the solar spectral distribution, mainly in the $\mathrm{R}$ and FR wavelength band, influence plant photomorphogenesis by means of the phytochrome and cryptochrome. The phytochrome response is characterized in terms of radiation rate in the red wavelengths $(\mathrm{R}, 600-700 \mathrm{~nm})$ to that in the farred radiation (FR, $700-800 \mathrm{~nm}$ ), i.e. the $\mathrm{R} / \mathrm{FR}$ ratio. The effects of the blue radiation $(\mathrm{B}, 400-500 \mathrm{~nm})$ is investigated by the ratio between the blue radiation and the far-red radiation, i.e. the $\mathrm{B} / \mathrm{FR}$ ratio. A BLUE net, a RED net, a YELLOW net, a PEARL net, a GREY net and a NEUTRAL net were tested in Bari (Italy), latitude $41^{\circ} 05^{\prime} \mathrm{N}$. Peach trees were located in pots inside the greenhouses and in open field. The growth of the trees cultivated in open field was lower in comparison to the growth of the trees grown under the nets. The RED, PEARL, YELLOW and GREY nets increased the growth of the trees more than the other nets. The nets positively influenced the fruit characteristics, such as fruit weight and flesh firmness.

Keywords: solar radiation, R/FR ratio, photomorphogenesis. 
